\title{
Três novas espécies de Aphelandra R. Br. (Acanthaceae) para o Brasil
}

\author{
Sheila Regina Profice ${ }^{1}$
}

Recebido em 08/06/2004. Aceito em 11/04/2005

\begin{abstract}
RESUMO - (Três novas espécies de Aphelandra R. Br. (Acanthaceae) para o Brasil). São descritas e ilustradas três novas espécies brasileiras do gênero Aphelandra, A. grazielae Profice e A. hymenobracteata Profice ocorrentes no Estado do Espírito Santo e A. wasshausenii Profice exclusiva do Estado de Minas Gerais.
\end{abstract}

Palavras-chave: Aphelandra, Acanthaceae, Flora do Brasil, nova espécie

\begin{abstract}
Three new species of Aphelandra R. Br. (Acanthaceae) from Brazil). Three new Brazilian species of the genus Aphelandra, A. grazielae Profice and A. hymenobracteata Profice that occur in Espírito Santo State and A. wasshausenii Profice from the Minas Gerais State are described and illustrated.
\end{abstract}

Key words: Aphelandra, Acanthaceae, Flora of Brazil, new species

\section{Introdução}

Aphelandra R. Br. é um gênero neotropical com aproximadamente 200 espécies, apresentando entre outros caracteres diagnósticos ausência de cistólitos, corola distintamente bilabiada, quatro estames com antera monotecas e grãos de pólen tricolporado (Profice $\&$ Wasshausen 1993).

O estudo de material botânico do gênero Aphelandra solicitado por empréstimo a diversos herbários nacionais e estrangeiros, propiciou o reconhecimento de três espécies inéditas para a Ciência. Com a descrição das novas espécies ampliase para 40 o número de espécies desse gênero para o Brasil .

\section{Descrição e discussão}

Aphelandra grazielae Profice sp. nov.

Fig. 1-9.

A. grazielae Profice, A.gigantae, A. maximilianae, A. bahiensi, A. rigidae affinis, sed praecipue bracteis roseis et lanceolatis dignoscitur.

Subarbusto 1,0 m alt.; caule cilíndrico na região apical subquadrangular, glabrescente; folha com pecíolo levemente canaliculado, 1,0-2,5 cm compr.; lâmina lanceolada, 11,5-18,0 cm compr., 1,4-3,7 cm larg., ápice acuminado, base decorrente, raro inequilátera, margem inteira ou subcrenada, em ambas as faces glabriúscula. Inflorescência espiga densa, 4,0-6,0 cm compr.; bráctea rósea, imbricada, cartácea, lanceolada, 7,0-8,0 mm compr., 1,5-2,0 mm larg., ápice aculeado, base obtusa, margem serrilhado-mucronada, com 4-6 pares de acúleos, glanduloso-pilosa; bractéola lanceolado-ovada, 4,0-5,5 mm compr., 1,0-1,5 mm larg., côncava, ápice aculeado, paleácea, pubérula, com tricomas simples e glandulares; cálice 5,5-7,0 mm compr., lacínios paleáceos, pubérulos, com tricomas simples e glandulares, lanceolados, 1,0-1,5 mm larg., ápice aculeado; corola rósea, 2,0-2,3 cm compr., base 2,0 mm larg., fauce 3,0 mm larg., lábio superior bilobado 1,5 mm compr., 4,0 mm larg., lábio inferior, os lobos laterais ovados, 1,5 mm compr., 1,0 mm larg., obtusos, o mediano elíptico, 2,5 mm compr., 2,0 mm larg., obtuso, côncavo; antera $4 \mathrm{~mm}$ compr., apiculada, no dorso vilosa; filete 1,3 cm compr., na região apical viloso; estilete 1,5 cm compr., com ápice truncado. Fruto não observado.

Tipo: BRASIL. Espírito Santo: Município de Ibiraçu, Estação Ecológica do Morro da Vargem, ca. $19^{\circ} 53^{\prime}$ S e $40^{\circ} 23^{\prime} \mathrm{W}$, Trilha do Mirante 1, 26/V/1990,

1 Instituto de Pesquisas Jardim Botânico do Rio de Janeiro, JBRJ, Rua Pacheco Leão 915, CEP 22460-030, Rio de Janeiro, RJ, Brasil (sprofice@jbrj.gov.br) 
H. Q. Boudet Fernandes 2930 et al. (Holótipo MBML; Isótipos RB, VIES, UEC, SPF).

Ocorre na floresta pluvial baixo-montana do Estado do Espírito Santo, entre 300 e $400 \mathrm{~m}$ de altitude. A. grazielae, pela forma da margem da bráctea, pode ser associada ao grupo de espécies de margem serrada ou serrilhado-mucronada (A. gigantea (Rizzini) Profice, A. rigida Glaz. ex Mildbr, A. maximiliana (Nees) Benth. e A. bahiensis (Nees) Wassh.) diferindo das espécies deste grupo pela bráctea lanceolada de cor rósea.

O epíteto específico é uma homenagem à Dra. Graziela Maciel Barroso, cuja vida profissional exemplar foi dedicada ao estudo da ciência botânica e à formação científica de inúmeros professores e pesquisadores no Brasil.

\section{Aphelandra hymenobracteata Profice, sp. nov.}

Fig. 10-16.

Distinguitur etiam haec species a congeneribus facilime bracteis oblongo-lanceolatis, utrinque nervis manifestis et bracteoleis linearibus et membranaceis.

Subarbusto 1,0 m alt.; caule cilíndrico, glabrescente, na região apical estrigoso-pubescente; folha subséssil, pecíolo $0,5 \mathrm{~cm}$ compr.; lâmina lanceolada, 16,0-22,0 cm compr., 4,0-6,0 cm larg., ápice agudo ou acuminado, base decorrente, margem inteira ou subcrenada, pubescente em ambas as faces. Inflorescência espiga densa, 4,5-14,5 cm compr.; bráctea imbricada, membranácea, nervuras conspícuas, oblongo-lanceolada, 15,0-19,0 mm compr., 5,0-8,0 mm larg., ápice apiculado, base obtusa, margem inteira, cíliada, glanduloso-pilosa em ambas as faces; bractéola membranácea, com indumento semelhante ao da bráctea, linear, 5,6-7,5 mm compr., 1,0 mm larg., ápice agudo; cálice 10,0-12,5 mm compr., lacínio posterior lanceolado-ovado, os laterais e os anteriores lanceolados, 1,0-2,0 mm larg., ápice acuminado, os segmentos pubérulos, com tricomas simples e glandulares; corola coccínea, 2,5-3,0 cm compr., base 1,5-2,0 mm larg., fauce 2,0-3,0 mm larg., lábio superior bilobado 1,5-2,0 mm compr., 3,0 mm larg., lábio inferior os lobos laterais oblongos, 1,5-2,0 mm compr., 1,5 mm larg., o mediano suborbicular, 2,0-2,5 mm compr., 2,0-2,5 mm larg.; antera 4,5 mm compr., apiculada, no dorso vilosa; filete $0,9-1,1 \mathrm{~cm}$ compr., na região apical viloso; estaminódio 1,0 mm compr.; estilete com ápice truncado, 1,3 cm compr. Fruto elipsóide, 14,0-20,0 mm compr.
Tipo: BRASIL. Espírito Santo: Santa Teresa, Alto do Julião, 14/VI/1984, W. Piziolo 129 (Holótipo MBML; Isótipo RB).

Espécie exclusiva da floresta pluvial baixomontana do Estado do Espírito Santo. A. hymenobracteata diferencia-se das demais espécies pelas brácteas e bractéolas de consistência membranácea, bráctea oblongo-lanceolada, com nervuras evidentes em ambas as faces e bractéola linear.

$\mathrm{O}$ epíteto hymeno refere-se à consistência membranácea das brácteas e bractéolas.

\section{Aphelandra wasshausenii Profice, sp. nov.}

Fig. 17-22.

Affinis est A. hymenobracteatae et $A$. schottianae, sed praecipue bractae lanceolato-ovata, concava et calyce glabro differt.

Arbusto 1,0-3,0 m alt.; caule cilíndrico, glabrescente, na região apical estrigoso-pubescente; folha com pecíolo canaliculado, estrigoso-pubescente, 1,0-2,0 cm compr.; lâmina oblanceolada, 9,0-24,0 cm compr., 3,0-5,2 cm larg., ápice acuminado, às vezes, levemente falcado, base decorrente, margem inteira ou subcrenada, glabriúscula em ambas as faces. Inflorescência espiga densa, às vezes, com aspecto mais laxo, 1,5-4,5 cm compr.; bráctea vinácea, imbricada, cartácea, lanceolado-ovada, 5,0-7,0 mm compr., 2,5-4,0 mm larg., côncava, ápice acuminado, base obtusa, margem inteira, em ambas as faces com indumento estrigoso-pubescente; bractéola subulada, 5,0-6,0 mm compr., 1,5 mm larg., ápice acuminado, pubérula, com tricomas simples e glandulares; cálice vináceo, 10,0-11,0 mm compr., lacínios glabros, lanceolados, 1,5-2,5 mm larg., ápice apiculado, margem hialina; corola vermelha, 3,5-5,0 cm compr., base 3,0-3,5 mm larg., fauce 4,5-5,0 mm larg., lábio superior bilobado 2,5 $\mathrm{mm}$ compr., 5,0 $\mathrm{mm}$ larg., lábio inferior com os lobos laterais oblongos, 3,0-3,5 mm compr., 2,5 mm larg., obtusos, o mediano, suborbicular, 4,0 mm compr., 3,0 mm larg.; antera 4,5 mm compr., apiculada, no dorso vilosa; filete $2,3-3,0 \mathrm{~cm}$ compr., na região apical viloso; estilete 3,0-3,5 cm compr., com ápice truncado. Fruto não observado.

Tipo: BRASIL. Minas Gerais: Araponga, Estouro, caminho da pedra do Boné, 5/IV/1986, M.F. Vieira 377, W.N. Vidal, M.R.R. Vidal \& M.F. Soares (Holótipo VIC). Parátipos: Araponga, Serra do Brigadeiro, Mata do Sérgio, Chapada Rochedo, M.F. Vieira 797, 10/VI/1993 (VIC); Viçosa, fazenda da Serra, 3/V/1930, Ynes Mexia 4661 (VIC, S, K, BM, 


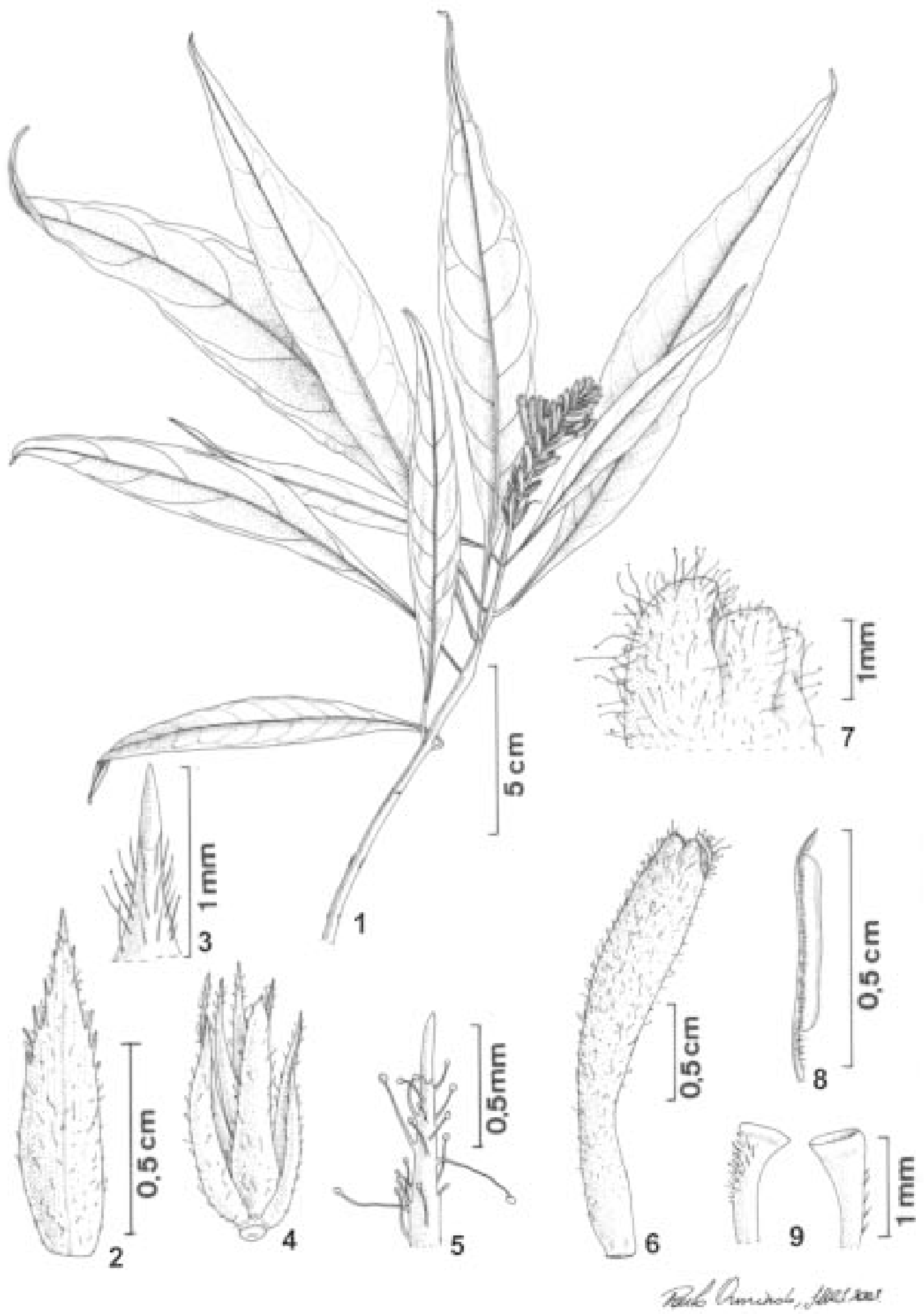

Figuras 1-9. Aphelandra grazielae Profice. 1. Detalhe do ramo florífero. 2. Bráctea. 3. Ápice da bráctea, evidenciando a pilosidade. 4. Bractéolas e cálice. 5. Lacínio do cálice, evidenciando a pilosidade. 6. Corola. 7. Lobos da corola. 8. Antera. 9. Estilete (H.Q.B. Fernandes 2930). 


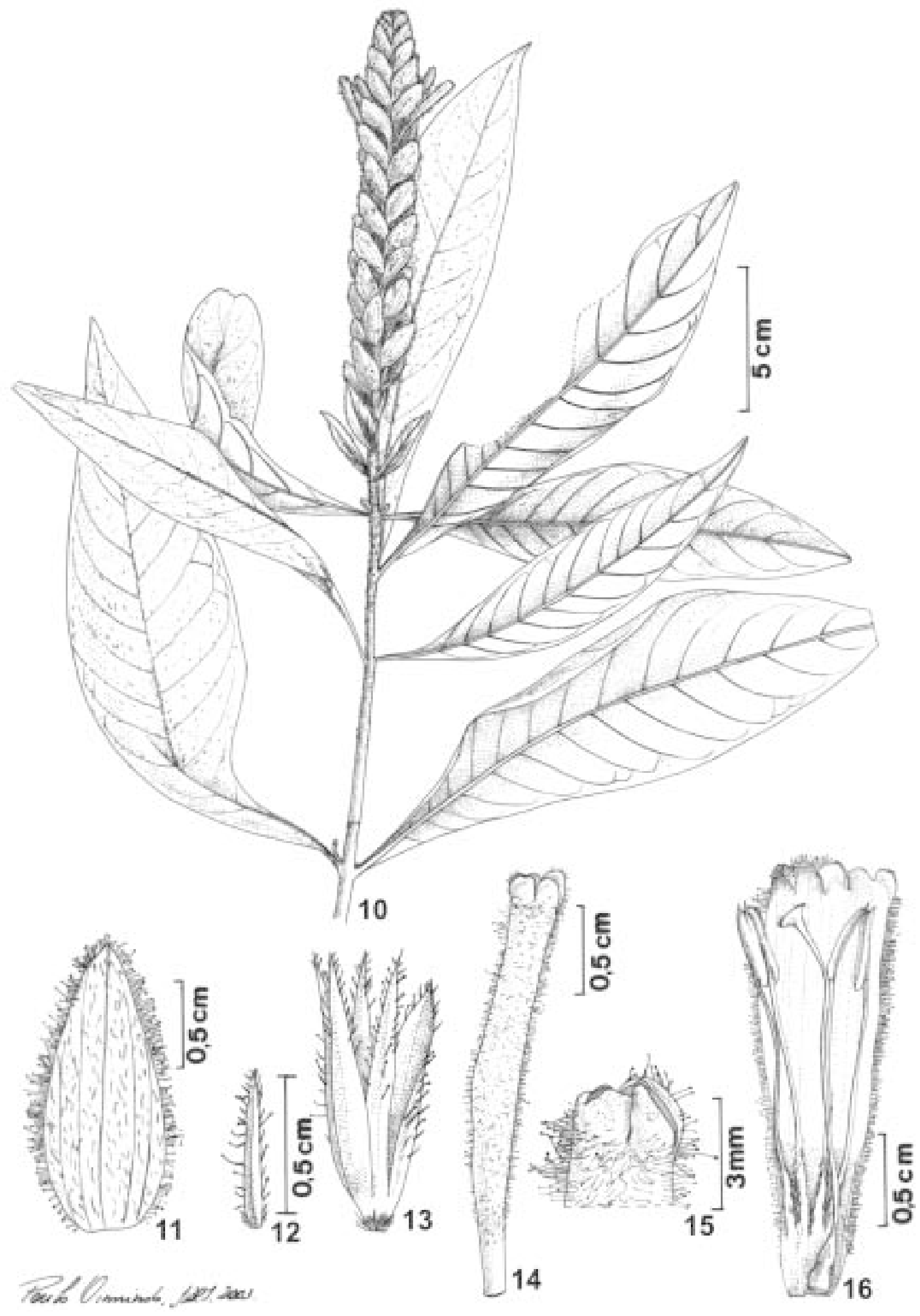

Figuras 10-16. Aphelandra hymenobracteata Profice. 10. Detalhe do ramo florífero. 11. Bráctea. 12. Brácteola. 13. Cálice. 14. Corola. 15. Lobos da corola. 16. Corola aberta, evidenciando o androceu e gineceu (W. Piziolo 129). 


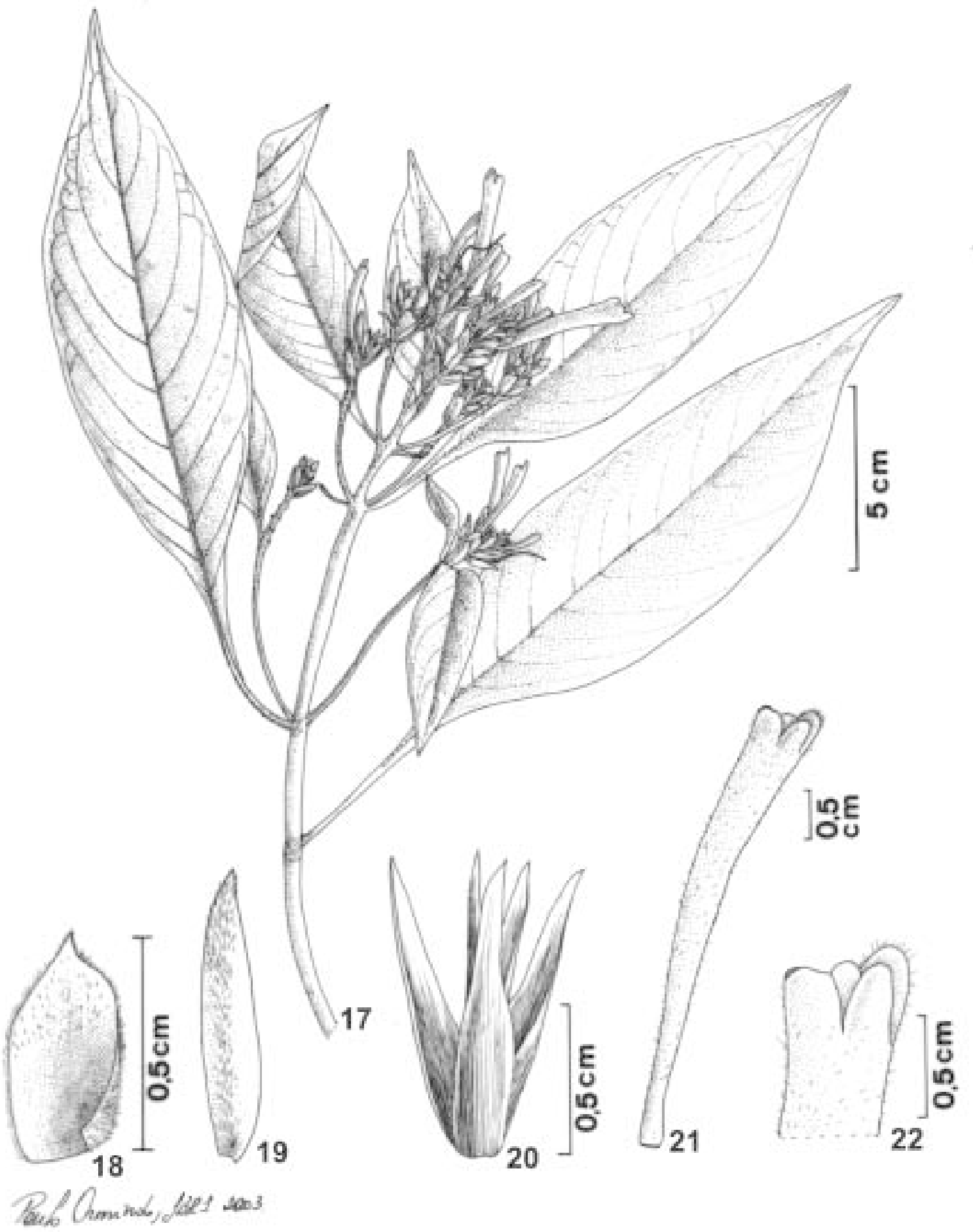

Figuras 17-22. Aphelandra wasshausenii Profice. 17. Detalhe do ramo florífero. 18. Bráctea, evidenciando a pilosidade. 19. Bractéola. 20. Cálice. 21. Corola. 22. Lobos da corola (M.F. Vieira et al. 377). 
NY, P); Carangola, Estrada para São Pedro da Gloria, $9 \mathrm{Km}$ da BR 116, 25/III/1992, C.Kameyama et al. 13 (SPF, RB).

Espécie exclusiva da floresta mesófila do Estado de Minas Gerais. A. wasshausenii e as duas espécies A. hymenobracteata e A. schottiana (Nees) Profice apresentam em comum a bráctea de margem inteira. A. wasshausenii diferencia-se destas pela bráctea lanceolado-ovada, côncava, com indumento estrigosopubescente em ambas as faces e cálice glabro.

O epíteto específico é uma homenagem ao Dr. Dieter Wasshausen, do Smithsonian Institution, por sua valiosa contribuição aos estudos taxonômicos das Acanthaceae neotropicais.

\section{Agradecimentos}

Aos Curadores dos herbários BM, MBML, NY, P, RB, SPF, VIC, VIES, pela consulta e/ou envio do material botânico; ao Smithsonian Institution, pela bolsa concedida para a consulta ao acervo desta instituição; ao Dr. Jorge Fontella Pereira, pela correção da diagnose latina; à Profa. Dra. Regina H.P. Andreata, pela orientação.

\section{Referência bibliográfica}

Profice, S.R. \& Wasshausen, D.C. 1993. Aphelandra espiritosantensis (Acanthaceae), a new species from Espírito Santo, Brazil. Novon 3(3): 280-283. 